\title{
The understanding of food fraud among consumers in Klang Valley, Malaysia
}

\section{Nur Nisaa Ahmad ${ }^{1}$, Siti Nurhayati Khairatun ${ }^{2 *}$}

Faculty of Food Science and Technology, Universiti Putra Malaysia, 43400 UPM Serdang, Selangor, Malaysia $^{1^{*}}$

Department of Food Science \& Management, Faculty of Food Science and Technology, Universiti Putra Malaysia, 43400 UPM Serdang, Selangor, Malaysia ${ }^{2}$ nisaa.ahmd@gmail.com ${ }^{1 *}$,snkhairatun@upm.edu.my ${ }^{2}$

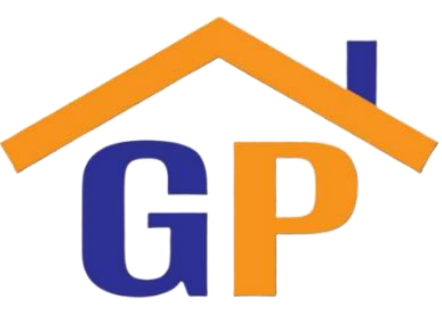

Article History

Received on 10 March 2021

$1^{\text {st }}$ Revision on 12 March 2021

$2^{\text {nd }}$ Revision on 15 March 2021

$3^{\text {rd }}$ Revision on 5 April 2021

Accepted on 16 April 2021

\section{Abstract}

Purpose: This study aimed to understand food fraud awareness and understanding from the Malaysian consumers' perspective.

Research methodology: Five face-to-face in-depth interviews using random purposive sampling were administered to obtain insights into Malaysian consumers' multiple realities. A peer review with an expert in quality control of the food supply chain was done to increase data trustworthiness and validate the findings.

Results: The findings indicated that awareness about food fraud among Malaysian consumers is relatively low. As consumers do not have the ability and necessary tools to evaluate food fraud, regulatory authority, certification bodies, and trade associations are responsible for protecting food integrity by mitigating food fraud.

Limitations: The study was self-funded and conducted in Klang Valley, Malaysia. Due to that, no generalization can be made from the data.

Contribution: This outcome can be used as a knowledge base for policymakers and trade industries in regulating the sustainability and integrity of the food industry, particularly for consumer outreach programs in disseminating accurate technical knowledge of food to the public.

Keywords: Food industry, Food inspection, Consumers education, Consumer protection, Consumer awareness, Food consumption

How to cite: Ahmad, N. N., \& Khairatun, S. N. (2020). The understanding of food fraud among consumers in Klang Valley, Malaysia. Journal of Sustainable Tourism and Entrepreneurship, 2(1), 31-40.

\section{Introduction}

Food fraud is estimated to cost the global food industry US $\$ 30$ to US\$40 billion yearly (PWC, 2017). From the simplest adulteration of mixing premium pure honey with sugar (Moore, Spink, Lipp, 2012); mixing olive oil with cheaper oil substitutes (Moore, Spink, Lipp, 2012); dilution of milk (Moore, Spink, Lipp, 2012); substitution of wild captured salmon with more inferior farmed species (Moore, Spink, Lipp, 2012); enhancement using dyes on low-quality spices (Moore, Spink, Lipp, 2012); to the far extreme of 2008 Chinese milk scandal of melamine addition in milk products which caused a few death in China; and 2013 horsemeat scandal of the European-wide substitution of processing beef with horsemeat (Lawrence, 2013), food fraud is an old problem but a rising issue needing much attention and prevention.

The complex nature and length of the supply chain made food fraud an emerging global threat with a larger scale and geographical coverage. Until recently, the transaction from farm to fork was as simple as from your local producers to buyers. Foods were produced locally and prepared at home without much processing. However, as technology evolves, the food sector's complexity and dynamism increase in tandem. For a start, the food supply chain becomes longer and interconnected globally with multiple 
points of transactions from producers to wholesalers to distributors to retailers before reaching consumers. It is common for a country to import food products from another continent, either because of the lack of supply or demand from consumers. Hence, food goes through a complex system involving production, postharvest handling, processing, storage, transport, and distribution before finally being sold through large or small retail outlets. Generally, we cannot ascertain what we eat and where it comes from anymore. It is a complex web with low traceability.

Food fraud is now becoming a topic of interest in the sphere of food safety, mainly due to the potential health threat it could harbour. Although food adulteration has long existed, the scale and geographical coverage pose emerging risks to public health. Food fraud is riskier than traditional food safety negligence as the adulterants are unconventional, motives are deliberate, and acts are intentional, which are designed to avoid detection.

Global Food Safety Initiative (GSFI) started in 2000 to help address food safety issues and build consumers' trust through advancing food safety management practices. It is the world's most extensive collaboration for food safety. Recently, GSFI included a new requirement for food fraud vulnerability assessment and a food fraud mitigation plan in the GSFI Guidance Document Version 7. Apart from that, FSSC 22000, a GFSI recognized scheme adopted from ISO 22000, has also been revised recently to version 5 in May 2019, incorporating Threats Analysis Critical Control Point (TACCP) and Vulnerabilities Analysis Critical Control Point (VACCP). Traditional food safety management system typically uses Hazzard Analysis Critical Control Point (HACCP) principles which focuses on preventing accidental contamination. However, HACCP might not effectively mitigate food's deliberate contamination since it is designed not to be detected. Hence, TACCP and VACCP are introduced to minimize food defence and food fraud risk, respectively.

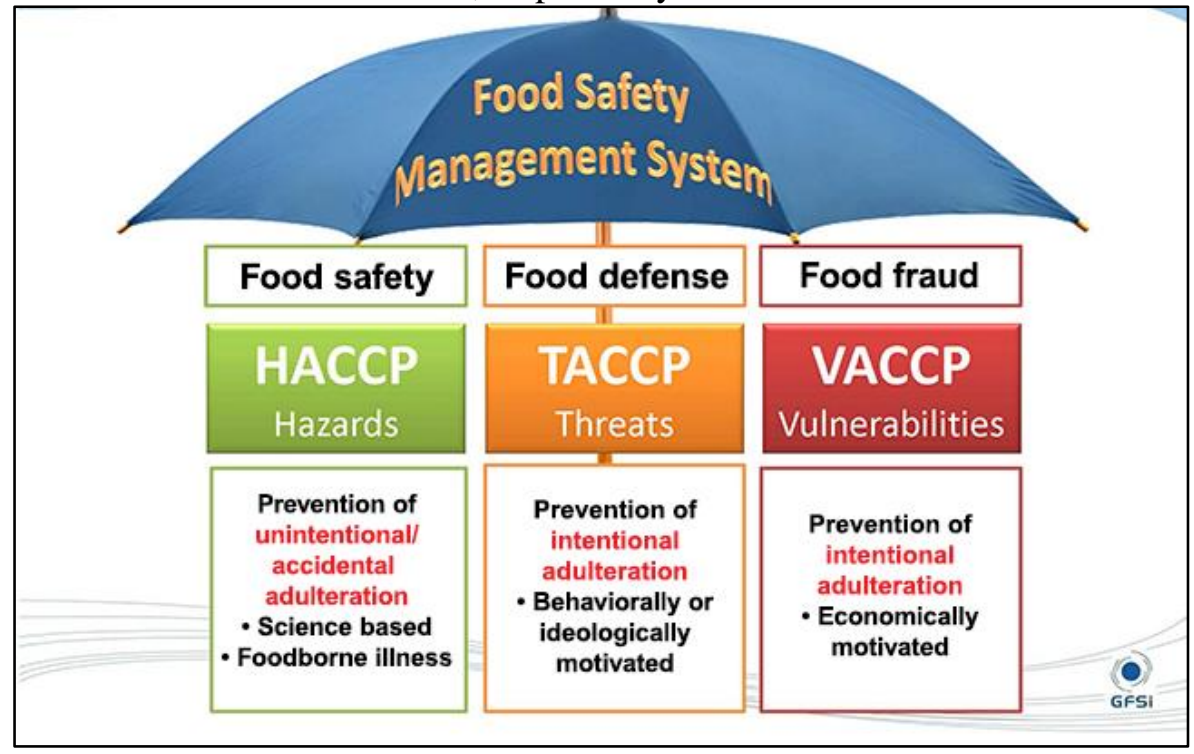

Figure 1: Approach to food fraud prevention

(Source: FSSC 22000, 2019)

While in Asia, we have $\mathrm{PwC}$ is leading its way in developing tools to ease companies transitioning into FSSC 22000. PwC is one of the "Big Four" accounting firms globally. It is interesting to note that a financial auditing firm recognizes food fraud as a type of crime equally catastrophic with financial fraud. Authorities and policymakers are doing their part as best as they could. However, since food fraud is an intentional act designed not to be detected, Dr Van Ruth (2017) proposed to look at food fraud vulnerabilities from a criminology standpoint using the Routine Activity Theory developed by Cohen and Felson in 1979. Like other organized crimes, food fraud's vulnerability heightens when opportunities and motivations are high and control measures where the risk of getting caught is low. Gullible consumers create convenient targets for motivated offenders to take advantage of. Since regulators are already making their effort to fight food fraud, consumers' participation is deemed necessary. 
Consumers' voice is seen to be making a presence in the industry. In the old times, with restricted communication channels, big players had the upper hand in dictating consumers' decisions. However, with the world becoming more virtual and borderless, modern consumers are more vocal in wanting more transparency in their purchases. Marketing has shifted tremendously in accommodating to consumers' demand for honesty. More and more brands are using marketing strategies such as organic, fair trade, and green products to promote an image of good business ethics and integrity.

Consumers are exposed to potential health risks in this food fraud scheme since they are the end-user in the food supply chain. Authorities and policymakers are responsible for facilitating trade while protecting consumers' rights. Standards and regulations are established to protect consumers' interests and ensure fair commercial practices. Food Safety and Quality Division (FSQ) of the Ministry of Health are responsible for coordinating food quality control, including enforcement of the law, monitoring, and consumer education. In many cases, we have seen our authority are very responsive in handling consumers' complaints in their food purchases. However, it is unclear the types of problems our Malaysian consumers commonly encounter in their food-related purchases, particularly in the context of food fraud.

A better-informed consumer makes better decision-making in their food purchases. As such, an insight into consumers' understanding of food fraud merits further investigation. This study's outcome can be used as a knowledge base for policymakers and trade organizations in regulating the sustainability and integrity of the food industry, particularly for consumer outreach programs in disseminating accurate technical knowledge of food.

Beyond the financial cost, food fraud can potentially lead to serious public health risks, damage the brand's reputation, and ultimately weaken public trust in authority (PWC, 2017). Hence, this raises the need for studies that try to understand consumers' understanding of food fraud. Hence, the main objective of this study is to explore Malaysian consumers' understanding of food fraud.

\section{Literature review}

\subsection{Defining food fraud}

In a report commissioned by the Department of Homeland Security, the operational definition of food fraud is a "collective term that encompasses the deliberate substitution, addition, tampering or misrepresentation of food, food ingredients or food packaging, or false or misleading statements made about a product for economic gain." (National Center for Food Protection and Defense, 2011). Simply put, it is the deliberate act of modification on food or food packaging to mislead and deceive the customers, usually for financial gain.

Since food fraud is a relatively new research area, terminologies such as food fraud, food adulteration, economically motivated food, or food crime are often interchangeably used in the academic realm. Fundamentally, it differs from other food risk concerns categorized through the cause of the fraudster's action and motivation. The Food Risk Matrix (Figure 2) developed by Spink and Moyer (2011) conceptualizes the concepts by differentiating them according to action (unintentional or intentional) and motivation (gain or harm).

\begin{tabular}{|c|c|l|c|}
\hline $\begin{array}{c}\text { Food } \\
\text { Quality }\end{array}$ & Food Fraud & Gain: Economic & Farm: Public Health/ \\
\hline \begin{tabular}{c|c} 
Food \\
Safety
\end{tabular} & $\begin{array}{c}\text { Food } \\
\text { Defense }\end{array}$ & $\begin{array}{l}\text { Economic/Terror } \\
\text { Unintentional }\end{array}$ Intentional & \\
\hline \multicolumn{2}{|c|}{ Action } &
\end{tabular}

Figure 2. The food risk matrix

(Source: Spink \& Moyer, 2011) 
Food fraud can be grouped into two distinct categories: food adulteration and food mislabeling. Food adulteration is the fraudulent act of substituting or diluting a high-value product with a less expensive or lower quality alternative to cut costs or increase the volume (Food Industry Asia, n.d.). Few of the classic example of food adulteration includes the substitution of extra virgin olive oil with cheaper vegetable oil varieties; addition of premier pure honey with the low-value sugar syrup; dilution of milk; substitution of wild captured salmon with more inferior farmed species; and enhancement using dyes on low-quality herbs and spices. Although these conventional adulterations may not necessarily pose a public health risk, it does bear impending potential threat from the extent a fraudster would go for financial gain. This is demonstrated in melamine adulteration in infant formula, which affected nearly 300,000 victims in China (Huang, 2014).

Another type of food fraud is food mislabeling. It is the misrepresentation or misdescription of food to deceive the consumers (Food Industry Asia, n.d.). Although food labelling might look trivial for some, rational consumers rely on product labeling information to make informed choices about the food they purchase and eat. For instance, consumers may wish to eat healthily through organically produced food or avoid certain animal products for religious reasons. Hence, food labelling is the bridge in providing accurate information from producers to consumers. Ideally, prepacked processed food should be authentic and accurately labelled to maintain consumers' confidence and trust in the food supply chain's integrity. However, unfortunately, that does not always happen. We have seen many fraudulent labeling cases due to businesses' sheer greed for financial gains, such as the European-wide substitution of processing beef with horsemeat in 2013 (Lawrence, 2013).

\subsection{Defining awareness and knowledge}

What are the differences between awareness and knowledge? These are the two positions identified in distinguishing between awareness and knowledge. One position proposed to consider awareness and knowledge as one construct and is used interchangeably. High knowledge can be translated as high awareness. Ishwar et al. (2016) studied the effects of knowing food adulteration among consumers. The terms awareness and knowledge are used interchangeably in their study. Knowledge about common adulterants in food items and their effect on consumers is translated as an assessment of their level of awareness. From the study, it was found that individuals with higher education status and socialeconomic status exercise good purchasing practices such as checking of nutrition label, expiry date and quality assurance logo from the authority before making a purchase.

The other position proposed to consider awareness and knowledge as two separate constructs. In a study of green products using the choice behavior model, Chen, Chen and Tung (2018) argued that consumers make a decision based on cognitive value (collective and individual), individual environmental literacy (environmental knowledge and awareness), extrinsic motivating attribute (government, media, and social influence) and perceived monetary value. Awareness affects consumer cognition which is formed through objective knowledge and subjective knowledge. Objective knowledge is defined as consumers' general understanding formed through objective facts. Whereas subjective knowledge is defined as consumers' specific understanding formed through experiences.

For our current study, we stand on the premise of awareness and knowledge as being two separate constructs. Awareness is regarded as a state of consciousness about something. An individual might be aware of something without having to have knowledge about it. For instance, an individual might be familiar with the existence of poverty in the city through personal encounters but might have zero objective knowledge about it.

Apart from that, there are two positions being identified in the research line relative to awareness, knowledge, and purchasing behavior. One position regards knowledge as a moderator between awareness and behavior. The degree of impact of awareness has on behavior is moderated by the level of knowledge. Sanlier and Karakus (2010) investigated criteria of nutrition, safety and reliability, cost and convenience in influencing consumers' shopping behavior. This study found consumer education significantly improves consumers' food shopping awareness and consciousness through increased levels of use of food labels. Hence, they suggested that as knowledge increases, awareness increases, which positively improves good purchasing practices in consumers. 
The other position regards awareness as a moderator between knowledge and behavior. The degree of impact knowledge has on behavior is moderated by the level of awareness. Sternisa et al. (2018) studied the construct of knowledge and awareness. Sufficient food safety awareness can stimulate the process of knowledge seeking and implementation. James, $\mathrm{Hu}$ and Leonce (2019) reported health and environmental consciousness stimulate favorable attitudes and beliefs which influence organic food consumption. As with any cognitive process, awareness is inextricably intertwined with knowledge. With the increase in exposure and changes in lifestyle, the shift in awareness and concerns about food safety prompts the search for more information and knowledge on product attributes which then influences their purchasing decision. Hence, the higher the awareness, the higher the utilization of knowledge brings about the behavior implementation.

Although the debate remains open, in the present research we have opted for considering knowledge as a moderator between awareness and behavior. The level of knowledge determines the degree of impact awareness has on attitude and behavior. Consumers' lack of scientific knowledge and information about food quality might be a constraint in their purchase of fraudulent food products.

\subsection{Research questions}

Thus, this study attempts to address the following research questions:

1. What do Malaysian consumers understand about food fraud?

2. How do Malaysian consumers develop an understanding of food fraud?

\section{Research methodology}

The research design of this study is an inductive qualitative exploratory study. This study explores what Malaysian consumers understand about food fraud. Face-to-face in-depth interviews were administered to answer the research questions. An interview protocol was developed as a guide to the researcher. These questions were formulated to answer the first research question of what consumer understands about food fraud and the second research question of how consumer develops their understanding of food fraud.

Six interviews were conducted with consumers from familiar buying places in Malaysia, namely supermarkets and convenience stores in Klang Valley, Malaysia. Sampling was done until data saturation was reached (Saunders et al., 2018). In this study, the researcher stopped conducting interviews when similar answers were received repeatedly.

Random purposive sampling was chosen for this study to represent better the different demographic backgrounds and multiple realities of Malaysian consumers. A mall-intercept interview was done. Random consumers were asked to participate in the study with the condition of being the primary grocery shopper in their household. The participants were from different ages, ethnicities, incomes, and genders to keep the demography mixed and representative (Hussain et al., 2020). The informants' background is as below:

Informant 1 (IF1)
Informant 2 (IF2)
Informant 3 (IF3)
Informant 4 (IF4)
Informant 5 (IF5)
Informant 6 (IF6)

: Female, late 20s, married, Malay

: Female, early 30s, single, Chinese

: Female, early 30s, married, Malay

: Female, early 20s, single, Bachelor's degree student, Malay

: Male, early 20s, single, Bachelor's degree student, Malay

: Male, late 40s, married, Malay

Although many qualitative studies involved a careful selection of informants, the random method is proven beneficial if the survey takes the form of a "collective case study" (Shenton, 2004). A random sampling of individuals allows the researcher to gain greater knowledge of a wider group and reduces researcher bias in selecting participants by addressing the "unknown influences" within the study. Nonetheless, the downside of random sampling is the absence of control over the type of informants chosen. As expected, some participants were a bit more reserved, less cooperative, and less articulate during the data collection process. 
After approaching the participants, the researcher informed the research's purpose and asked for their permission before starting the interview. The researcher tries her best to create an encouraging and favourable environment to enable the participants to feel comfortable expressing their opinions (Hussain et al., 2020). With informed consent from the informants, interviews were audio-recorded during the session and later transcribed. The interviews' duration was approximately 10 to 30 minutes, depending on the consumers' cooperation and willingness. The non-response or attrition rate was lowered significantly by the researchers' ability to engage with the informant. The data were analyzed using thematic analysis.

In 2006, Braun and Clarke (2006) proposed the six steps in a thematic analysis of becoming familiar with the data, generating initial codes; searching for themes; reviewing the themes; defining and naming the themes, and producing the final report. Nowell et al. (2017) occurred that thematic analysis is a method for identifying, analyzing, organizing, describing, and reporting themes found within a data set. The verbatim transcripts were analyzed line-by-line manually using axial coding to form themes from the codes developed. Peer review with an expert in the industry who is well-versed in the food supply chain and quality control was done to increase data trustworthiness, complement the findings, and understand the phenomena from multiple perspectives.

\section{Results and discussions}

Findings from verbatim transcripts conclude that the understanding of food fraud is generally low in Malaysian consumers. It was observed that low awareness about food fraud might reconstitute to two possible reasons:

1) either they have never previously experienced purchasing fraudulent food or

2) they were not aware of the purchase being considered food fraud, thus not being conscious of the problem.

From the interviews, all the consumers approached are uncertain about food fraud. Understandably, food fraud is a new topic of interest in the academic realm. Moreover, this terminology has only been recently defined and set apart from the other common food safety and quality issues. Hence this terminology is still an uncommon knowledge to the public.

When the definition of food fraud was explained, consumers' understanding of food fraud is limited to their knowledge and experience recollection. Their recollection is only limited to visible quality attributes that can be assessed superficially through post-consumption of the product's sensory taste and efficacy. All informants pointed out mislabelling and misrepresenting products such as overclaimed products and counterfeit products as examples of food fraud. Only one informant pointed out the ingredients' tempering as an example of food fraud. As agreed through the peer review, experts concurred that it is implausible a customer could assess the presence of food adulteration since technology has made it difficult and almost impossible to detect.

Expert: "Example, sausages. Because sausages, they are also listed in the Food Act. As long as, because sausages they have a lot of grey line if you ask me. Some would be like, very affordable, but that one mainly is from starch ... or they don't have, maybe low percentage of meat but they enhance with all the ISP, to meet the protein content listed in the Food Act. Basically, they just add ISP, to increase the protein content."

Expert: "... Like the protein content ... actually, the protein content is not really from meat, maybe they use like soy protein, to enhance. Like the alginate, because birds nest, you cannot count anything, because the protein in high heat, they are already denatured. So even if it is the real protein, the real bird nests la so-called, even you go for sanitation, halfway already denatured, so the protein content also becomes lesser, so eventually, you put in alginate.

In a study by Nasreen and Ahmed (2014), Public Health Food Laboratory, a food testing lab revealed that conforming to a test parameter in a standard does not necessarily translate to purity. Artificial 
ingredients can be added to mask adulteration by manipulating the test results within acceptable limits. For example, cheaper vegetable proteins, like soy proteins, are added into pasteurized milk to comply with the food standard's expected protein content.

To answer the second research question on understanding food fraud, informants must first have an awareness about it. As mentioned earlier, awareness is in its infancy. Hence, the data obtained are more fitting to address how Malaysian consumers develop good purchasing decisions in protecting their rights from falling victim to all food safety and quality issues. The research question was altered to fit the situation at hand better.

$$
\begin{aligned}
& \text { From : "How do customers develop an understanding of food fraud?" } \\
& \text { To : "How do customers protect their rights and make a good purchasing } \\
& \text { decision?" }
\end{aligned}
$$

Consumers develop good purchasing decisions through pre-consumption and post-consumption evaluation. Post-evaluation involves judgment after purchase. If their consumption experience does not match their expectations, the customer will likely not make a second purchase. On the other hand, evaluation before buying is influenced by 1) market survey, 2) brand reputation, and 3) product marketing.

During the market survey, pricing and product benefit determine their purchase.

Informant 6: " "...I will first do my survey, explore the pricing. Usually, I will go with my wife. Survey here and there and compare the price to how to we want it to be. and later consult friends."

Consumers also look at quality assurance certification before making a purchase. It was observed that consumers who have confidence in local regulatory enforcement control and trust in regulatory authority consider quality assurance certification a good purchasing practice.

Informant 6: "Commonly, iffood-related products, I will refer to the Ministry of Health, either it is a registered product or not. For example, when we go to the night market, you can find them selling supplements. That, I usually don't buy"

On the other end, there is also a segment of consumers who have low trust in authority. Quality assurance certification will have no significant influence on their food purchase. This low trust in quality assurance certification might be due to the low awareness of Malaysia's regulation. After explaining the food registration in Malaysia, the misconception and skepticism dissolved from the conversation.

Informant 1: "Ahhh, I thought because she (Neelofa, a celebrity) is famous, so she can overclaim her products."

Apart from that, brand reputation plays a huge role in customer purchases. All the informants concurred that buying products from well-established brands is the safest option. Customers commonly purchase their familiar brand since they already have a fair evaluation of the product quality.

\section{Informant 2: "We will choose the brand that we frequently listen to and hear of."}

Besides that, product marketing influences consumers purchasing decisions. Consumers are highly influenced by online marketing and peer recommendation. Trust is built through information from social media and word of mouth, leading to the product's purchase (Kooli, Al Habsi \& Abadli, 2018).

Informant 2: "From some social media."

Informant 6: "...I will go survey, get to know the price, and later ask friends about it." 
Lastly, the study found out that Malaysian consumers are mostly passive, most likely because it is too troublesome to go the extra mile to stand for their rights compared to the small financial damage incurred. Hence, consumers' action is highly dependent on the degree of impact or consequences suffered by consumers.
Interviewer: "What do you feel after you bought the product and realized that it has expired. What's the next action that you do? Do you go back to the store, or do you make a complaint..."
Informant 2: "No, I will just eat that food. As soon as possible."

Even with the understanding of customers' rights and knowing the procedure to mitigate the situation, customers still decide to close an eye to the problem and take it lightly.
Informant 6:
"If the product has expired and the store is nearby, I will just go back to the store and as for an exchange or a refund."
Informant 2: "No, I will just eat that food. As soon as possible."

\section{Conclusion}

To date, awareness about food fraud among Malaysian consumers is relatively low. This study's powerful insight has revealed that mitigating food fraud practically falls into the hand of authority, certification bodies, and trade associations in protecting food integrity. Although some customers might be aware of food fraud, they can only superficially assess the quality through its taste and postconsumption experience. Consumers do not have the ability and necessary tools to evaluate food adulteration since it is the manipulation of product quality at the core. Nonetheless, awareness programs are still deemed essential for consumer empowerment. Ultimately, consumer demand dictates industry direction. Industry players will always find new technology to cut costs by manipulating the quality or quantity of production volume. However, with consumers' demand for honesty and transparency, manufacturers will take more responsibility to appease consumers' needs and protect their brand's reputation.

\section{Limitation and future recommendations for future research}

This research has its shortcomings. Firstly, member-check cannot be done since informants are random consumers who are willing to participate in the interview at that very moment only. There were no ways in contacting the informants after data transcription.

Secondly, one-to-one interviews might have their downside as some consumers did felt pressured to be questioned on the spot. Future research is recommended to be conducted in a focus group discussion, which will leverage some time for consumers to recall back their past experiences and give a more meaningful response. Apart from that, having a focus group discussion helps selectively choose informants interested in participating in the research endeavor. They will be more willing to allocate the time needed during the data collection process. Member-check can also be done for data validation.

Future research is also suggested to focus the study on one specific food category, either in fresh produce, processed food, or premium food. It is based on the premise the degree of financial impact might drive different proactive and reactive actions in standing for their right as a consumer. Moreover, a more specific case study within the general case study of food fraud could be examined, for example, adulteration in olive oil, honey, meat, or milk. By being specific, customers will focus more on their recollection and give clearer insight.

Besides that, studies examining food integrity from the manufacturers' point of view could facilitate consumer protection. Working with the industry may be a bit of a challenge, especially in the pursuit of finding the right industry partners to obtain insights into reality from the highly profit-oriented commercial world. Collaboration between academic universities, authorities, and related individuals at the food supply chain's front line could provide beneficial insights in developing a more practical, holistic, and thorough regulation to protect consumers' right to get what they paid for. 


\section{Acknowledgement}

The authors would like to thank everyone who has contributed directly or indirectly to the writing of this paper.

\section{References}

Braun, V. \& Clarke, V. (2006). Using thematic analysis in psychology. Qualitative research in Psychology, 3(2), 77-101.

Chen, C.C., Chen, C.W. \& Tung, Y.C. (2018). Exploring the consumer behavior of intention to purchase green products in belt and road countries: an empirical analysis. Sustainability, 10(3), 854. https://doi.org/10.3390/su10030854

Cohen, L. \& Felson, M. (1979). Social change and crime rate trends: A routine activity approach. American Sociological Review, 44(4), 588-608

Food Act 1983. (2012). Retrieved from http://fsq.moh.gov.my

Food Industry Asia. (n.d.). Food fraud: Understanding the impact of food fraud in Asia. Retrieved from https://foodindustry.asia/documentdownload.axd?documentresourceid=30310

FSSC 22000. (2019). FSSC 22000 version 5. Retrieved form https://www.fssc22000.com/news/fssc22000-publishes-scheme-version-5/

Global Food Safety Initiative. (2017). Version 7.1 of GSFI's benchmarking requirements furthering harmonization. Retrieved from https://mygfsi.com/press_releases/version-7-1-of-gfsisbenchmarking-requirements-furthering-harmonisation/

Huang, Y. (2014). The 2008 Milk Scandal revisited. Forbes. Retrieved from https://www.forbes.com/sites/yanzhonghuang/2014/07/16/the-2008-milk-scandalrevisited/\#75d025b14105

Hussain, S., Melewar, T.C., Priporas, C.V. \& Foroudi, P. (2020), Examining the effects of advertising credibility on brand credibility, corporate credibility and corporate image: a qualitative approach. Qualitative Market Research, 23(4), 549-573. doi.org/10.1108/QMR-12-2017-0175

Ishwar, S., Dudeja, P., Shankar, M.P., Swain, S. \& Mukherji, S. (2016). 'Jago Grahak Jago': A crosssectional study to assess awareness about food adulteration in an urban slum. Medical Journal Armed Forces India, 74(1), 57-60.

James, M.X., Hu, Z. and Leonce, T.E. (2019). Predictors of organic tea purchase intentions by Chinese consumers: Attitudes, subjective norms and demographic factors. Journal of Agribusiness in Developing and Emerging Economies, 9(3), 202-219. https://doi.org/10.1108/JADEE-03-2018-0038.

Kooli, C., Al Habsi, A., \& Abadli, R. (2018). Celebrity Endorsement and Its Effect: Arabic World Perspectives. International. Journal of Advanced Research, 6(2), 182-188.

Lawrence, F. (2013). Horsemeat scandal: The essential guide. The Guardian. Retrieved from https://www.theguardian.com/uk/2013/feb/15/horsemeat-scandal-the-essential-guide

Moore, J.C., Spink, J., \& Lipp, M. (2012). Development and application of a database of food ingredient fraud and economically motivated adulteration from 1980 to 2010. Journal of Food Science, 77(4), R118- R126

Nasreen, S. \& Ahmed, T. (2014). Food adulteration and consumer awareness in Dhaka City, 19952011. Journal of Health Population and Nutrition, 32(3), 452-464. Retrieved from https://www.ncbi.nlm.nih.gov/pmc/articles/PMC4221451/

National Center for Food Protection and Defense. (2011). Backgrounder: Defining the public health threat of food fraud. Retrieved from https://foodfraud.msu.edu/wpcontent/uploads/2014/07/food-fraud-ffg-backgrounder-v11-Final.pdf

Nowell, L. S., Norris, J. M., White, D. E. \& Moules, N. J. (2017). Thematic Analysis: Striving to meet the trustworthiness criteria. International Journal of Qualitative Methods, 16, 1-13.

PWC. (2017). Food fraud vulnerability assessment. Retrieved from https://www.pwc.com/gx/en/services/food-supply-integrity-services/food-fraud-vulnerabilityassessment.html

Sanlier, N. \& Karakus, S.S. (2010). Evaluation of food purchasing behaviour of consumers from supermarkets. British Food Journal, 112(2). 140-150.

https://doi.org/10.1108/00070701011018824 
Saunders, B., Sim, J., Kingstone, T., Baker, S., Waterfield, J., Bartiam, B., Burroughs, H. \& Jinks, C. (2018), Saturation in qualitative research: exploring its conceptualization and operationalization. Quality and Quantity, 52(4), 198301907

Shenton, A. K. (2004). Strategies for ensuring trustworthiness in qualitative research projects. Education for Information, 22, 63-75. Retrieved from pdfs.semanticscholar.org/cbe6/70d35e449ceed731466c316cd273032b28ca.pdf

Spink, J. \& Moyer, D.C. (2011). Defining the public health threat of food fraud. Journal of Food Science, 76(9), R157-R163. doi.org/10.1111/j.1750-3841.2011.02417.x

Sternisa, M., Smole Mozina, S., Levstek, S., Kukec, A., Raspor, P. and Jevsnik, M. (2018). Food safety knowledge, self-reported practices and attitude of poultry meat handling among Slovenian consumers. British Food Journal, 120(6), 1344-1357. https://doi.org/10.1108/BFJ06-2017-0360.

Van Ruth, S.M., Huisman, W., \& Luning, P.A. (2017). Food fraud vulnerability and its key factors. Trends in Food Science \& Technology, 67, 70-75. doi.org/10.1016/j.tifs.2017.06.017. 